\title{
Sosialisasi Meningkatkan Wirausaha Masyarakat di Era Digital
}

\author{
Yenni Sofiana Tambunan ${ }^{1)} \mid$ Mansur Tanjung ${ }^{2)} \mid$ Nelly Azwarni Sinaga $^{3)} \mid$ Furi Windari $^{4)}$ \\ 1,2,3,4) Sekolah Tinggi Ilmu Ekonomi Al Washliyah \\ yennisofiana@gmail.com | tanjungmansur@yahoo.co.id | nellysinaga1964@gmail.com | \\ furi.windari@gmail.com
}

\begin{abstract}
ABSTRAK : Dari beberapa observasi langsung di lapangan, menunjukkan minat usaha masyarakat Kabupaten Tapanuli Tengah masih tergolong rendah, hal tersebut dapat dilihat masih sedikitnya hasil kreasi masyarakat yang meramaikan lalu lintas barang, padahal Kabupaten Tapanuli Tengah adalah daerah pesisir yang kaya akan hasil laut dan daerah pariwisata dengan mengandalkan keindahan daerah pantai. Masih minimnya produksi olahan dari hasil laut dan banyak cendramata yang diperkenalkan pada. Kemudian masih banyaknya jumlah Ibu Rumah Tangga (IRT) yang hanya bekerja rumah, tanpa memanfaatkan peluang perdagangan dengan sarana digital. Adapun tujuan yang ingin dicapai dalam kegiatan Pengabdian kepada Masyarakat ini adalah menumbuhkan minat berwirausaha masyarakat dengan peluang sarana digital khususnya untuk Ibu Rumah Tangga Kelurahan Huta Balang, Kabupaten Tapanuli Tengah. Kegiatan sosialisasi "Meningkatkan Wirausaha Masyarakat di Era Digital" dilaksanakan di gedung Madrasah Al Ikhsan di Kelurahan Huta Balang, Kecamatan Badiri, Kabupaten Tapanuli Tengah pada hari Sabtu, Tanggal 17 April 2021. Kegiatan terlaksana sesuai dengan tujuan dan rencana. Kegiatan ini mendapat sambutan yang baik dari masyarakat yaitu IRT dan Pemerintah daerah setempat, yaitu Lurah dan Kepling. Kegiatan ini dapat memberikan tambahan semangat dan pengetahuan tentang peluang usaha dengan peluang di era digital saat ini.
\end{abstract}

Kata Kunci : Meningkatkan Wirausaha Masyarakat di Era Digital

\section{Latar Belakang Masalah}

\section{Pendahuluan}

Menteri Koperasi dan UKM Teten Masduki menegaskan bahwa menjadi seorang wirausaha di masa pandemi Covid-19 adalah pilihan yang paling tepat. "Alasannya, karena banyak perusahaan yang merumahkan karyawannya. Bahkan, ada yang sudah melakukan PHK," Terlebih lagi, rasio kewirausahaan Indonesia baru sekitar 3,47\%. Dan ini cukup rendah bila dibandingkan dengan sesama negara ASEAN seperti Singapura yang mencapai 8,76\%, Thailand 4,26\% serta Malaysia 4,74\%. "Beberapa ahli menyebutkan bahwa suatu negara disebutkan maju apabila rasio wirausaha berkisar 1014 persen," ucap Menkop UKM (https://ekonomi.bisnis.com).

Kurun waktu 10 tahun belakangan pendidikan kewirausahaan (entrepreneurship) di Indonesia menjadi trend. Sampai detik ini semangat kewirausahaan di perguruan tinggi bahkan sekolah menengah dan dasar di Indonesia terus tumbuh dan berkembang melalui penyelenggaraan pendidikan kewirausahaan. Apa yang menyebabkan semangat kewirausahaan di Indonesia begitu menggelora? Jawabannya sederhana, karena Indonesia saat ini butuh perjuangan yang lebih serius dalam mengejar ketertinggalan dari negara-negara lain dalam kemajuan perekonomian. Bahkan yang menjadi permasalahan adalah kemajuan ekonomi negaranegara tersebut antara lain ditentukan oleh jumlah pengusahanya (Heri Kuswara dalam Adri, dkk 2019).

Teknologi telah mengubah cara manusia berkomunikasi dan berinteraksi. Bahkan memberi warna baru bagi perkembangan bisnis di indonesia bahkan di dunia. Perkembangan teknologi menjadi 
faktor utama globalisasi. Perkembangan teknologi mengubah analog menjadi digital. Beberapa aspek yang dulu bersifat lokal dan sempit jangkauannya, kini telah beralih ke jangkauan yang lebih luas bahkan global. Ditinjau dari aspek sosial, Era digital memungkinkan manusia berinteraksi bahkan berbisnis dengan manusia di belahan negara lain dengan sangat mudah. Era digital memungkinkan masyarakat melakukan jual beli tanpa adanya tatap muka. (Novita dan Santoso, 2021).

Dampak era digital telah memberikan perubahan pada dinamika kehidupan, diantaranya adalah dinamika kehidupan dunia usaha (bisnis). Ini tak dapat dipungkiri karena era tersebut membuat akses peluang usaha akan lebih mudah dan cepat. Tanpa modal besar dan tempatpun orang bisa menjalankan usaha dengan memanfaatkan teknologi digital baik melalui facebook, instagram, website maupun media sosial lainnya. Market place akan terbentuk dengan lebih mudah melalui pemanfaatan teknologi tersebut (Maryati, Masriani, 2019).

Menurut sebuah laporan yang dirilis oleh Temasek, Google, dan Bain\&Co pada 2019, diperkirakan tingkat pertumbuhan ekonomi digital di Indonesia mencapai 49 persen per tahun. Pertumbuhan sektor e-commerce Indonesia bahkan diprediksi melampaui angka US\$ 130 miliar pada 2025. Ini menjadikan Indonesia sebagai salah satu negara dengan kekuatan ekonomi digital terbesar di dunia. Pemerintah, pelaku usaha hingga akademisi sepakat bahwa ekonomi digital menjadi salah satu penyelamat perekonomian nasional saat menghadapi pandemi Covid-19. Ekonomi digital terbukti tetap tumbuh di tengah lesunya berbagai bidang pada masa pandemi ini. (https://law.uii.ac.id).

Di Indonesia sendiri hanya sekitar 3\% dari jumlah penduduk yang berjumlah lebih dari 250 juta jiwa yang menjadi entrepreneur. Meskipun rasio wirausaha di Indonesia sudah melampaui standar internasional, yaitu sebesar 2\%, tetapi Indonesa perlu mendorong lagi untuk mengejar capaian negara tetangga di Asia Tenggara. Misalnya, Singapura saat ini sudah mencapai angka 7\%, sedangkan Malaysia berada di level 5\%. Apabila dihitung dengan populasi penduduk Indonesia sekitar 260 juta jiwa, jumlah wirausaha nasional mencapai 8,06 juta jiwa. (Atmaja \& Verawati, 2021).

Masyarakat Kabupaten Tapanuli Tengah merupakan masyarakat yang sebagian besar tinggal di daerah pesisir pantai dan corak kehidupannnya sebagian besar layaknya kebiasaan-kebiasaan masyarakat pesisir yaitu mencari penghidupan dari sumber daya alam laut. Dari beberapa observasi langsung di lapangan, menunjukkan bahwa minat usaha masyarakat Kabupaten Tapanuli Tengah masih tergolong rendah, hal tersebut dapat dilihat masih sedikitnya hasil kreasi masyarakat yang meramaikan lalu lintas barang, padahal Kabupaten Tapanuli Tengah adalah daerah pesisir yang kaya akan hasil laut dan daerah pariwisata dengan mengandalkan keindahan daerah pantai. Masih minimnya produksi olahan dari hasil laut dan banyak cendramata yang diperkenalkan pada pengunjung dengan label daerah adalah produk yang dibeli dari kota-kota besar bukan hasil kreasi tangan masyarakat setempat. Kemudian masih banyaknya jumlah Ibu Rumah Tangga (IRT) yang hanya bekerja rumah, tanpa memanfaatkan peluang perdagangan dengan sarana digital. Untuk itu, kami sebagai Dosen dari kampus yang memiliki nama besar di daerah Sibolga- Tapanuli Tengah yaitu Sekolah Tinggi Ilmu Ekonomi (STIE) Al Washliyah Sibolga/Tapanuli Tengah melakukan Pengabdian kepada Masyarakat untuk menumbuhkan minat berwirausaha masyarakat khususnya Ibu-Ibu keluaharan Huta Balang, Kabupaten Tapanuli Tengah.

Sesuai dengan kewajiban dosen untuk melakukan Tridharma Perguruan Tinggi sesuai dengan Pasal 20 Ayat (2) UU No.20 Tahun 2003 Tentang Pendidikan Tinggi bahwa Perguruan tinggi berkewajiban menyelenggarakan pendidikan, penelitian, dan pengabdian kepada masyarakat (https://peraturan.bpk.go.id).

\section{Tujuan}

Adapun tujuan yang ingin dicapai dalam kegiatan Pengabdian kepada Masyarakat ini adalah menumbuhkan minat berwirausaha masyarakat dengan peluang sarana digital khususnya untuk Ibu Rumah Tangga Kelurahan Huta Balang, Kabupaten Tapanuli Tengah.

\section{Manfaat}

Diharapkan kegiatan ini memberikan beberapa manfaat untuk berbagai pihak yaitu :

1. Untuk Dosen yaitu mengaplikasikan ilmu yang dimiliki di masyarakat dan menunaikan kewajiban Tridharma Perguruan Tinggi. 
2. Untuk Masyarakat yaitu untuk memotivasi membuka usaha di era digital dan menambah wawasan bewirausaha.

3. Untuk pemerintah setempat yaitu untuk meningkatkan taraf ekonomi masyarakat dengan kemandirian berwirausaha dengan peluang sarana digital.

\section{Lokasi}

\section{$\underline{\text { Realisasi Kegiatan }}$}

Kegiatan sosialisasi "Meningkatkan Wirausaha Masyarakat di Era Digital" dilaksanakan di gedung Madrasah Al Ikhsan di Kelurahan Huta Balang, Kecamatan Badiri, Kabupaten Tapanuli Tengah.

Waktu

Sebelum kegiatan dilaksanakan perlu adanya persiapan berikut :

Tabel 1. Rincian Waktu Persiapan Sosialisasi

\begin{tabular}{|c|l|l|}
\hline No & \multicolumn{1}{|c|}{ Keterangan } & \multicolumn{1}{|c|}{ Waktu } \\
\hline 1 & Rapat Tim Dosen ke-1 30 Maret 2021 \\
\hline 2 & $\begin{array}{l}\text { Konsultasi dengan Lurah Huta Balang, Kecamatan Badiri, } \\
\text { Kabupaten Tapanuli Tengah, untuk meminta izin } \\
\text { pelaksanaan Sosialisasi }\end{array}$ & 01 April 2021 \\
\hline 3 & $\begin{array}{l}\text { Menetapkan hari, tanggal kegiatan, tempat dan peralatan } \\
\text { yang perlu dipersiapkan (Rapat Tim Dosen ke-2) }\end{array}$ & 03 April 2021 \\
\hline 4 & $\begin{array}{l}\text { Mempersiapkan materi kegiatan dan perlengkapan yang } \\
\text { diperlukan agar pelaksanaan dapat mudah dipahami, menarik } \\
\text { dan lancar }\end{array}$ & 2021 15 April \\
\hline 5 & $\begin{array}{l}\text { Pelaksanaan Sosialisasi, dimulai jam 08.00 sampai } \\
\text { dengan selesai. }\end{array}$ & 17 April 2021 \\
\hline 6 & \begin{tabular}{l} 
PELAPORAN \\
\hline
\end{tabular} & Mei 2021 \\
\hline
\end{tabular}

\section{Keanggotaan}

Tim dosen yang melakukan Pengabdian kepada Masyarakat (PkM) seluruhnya adalah dosen Sekolah Tinggi Ilmu Ekonomi (STIE) Al Washliyah Sibolga/Tap.Tengah dengan urutan kedudukan dan materi yang masing-masing dibawakan sebagai berikut :

Tabel 2. Keanggotaan dan Materi Masing-masing

\begin{tabular}{|c|l|l|}
\hline No & \multicolumn{1}{|c|}{ Nama } & \multicolumn{3}{|c|}{ Urutan Materi yang Dipaparkan } \\
\hline 1. & Mansur Tanjung & $\begin{array}{l}\text { Gambaran umum wirausaha masyarakat di Era } \\
\text { Digital saat ini. }\end{array}$ \\
\hline 2. & Yenni Sofiana Tambunan & $\begin{array}{l}\text { Peluang usaha yang memungkinkan di daerah } \\
\text { Kelurahan Huta Balang dengan peluang sarana } \\
\text { Digital }\end{array}$ \\
\hline 3. & Nelly Azwarni Sinaga & Etika hukum dalam bisnis Digital \\
\hline 4. & Furi Windari & Laporan Keuangan Binis Wirausaha \\
\hline 5. & Sinta Veronika Hutabarat & Aplikasi E-Commerce memudahkan bisnis Digital \\
\hline
\end{tabular}

\section{Dokumentasi Kegiatan}

Berikut dokumentasi kegiatan selama kegiatan Pengabdian kepada Masyarakat (PkM) dimana pesertanya adalah masyarakat Keluarahan Huta Balang, Kecamatan Badiri, Kabupaten Tapanuli Tengah. 


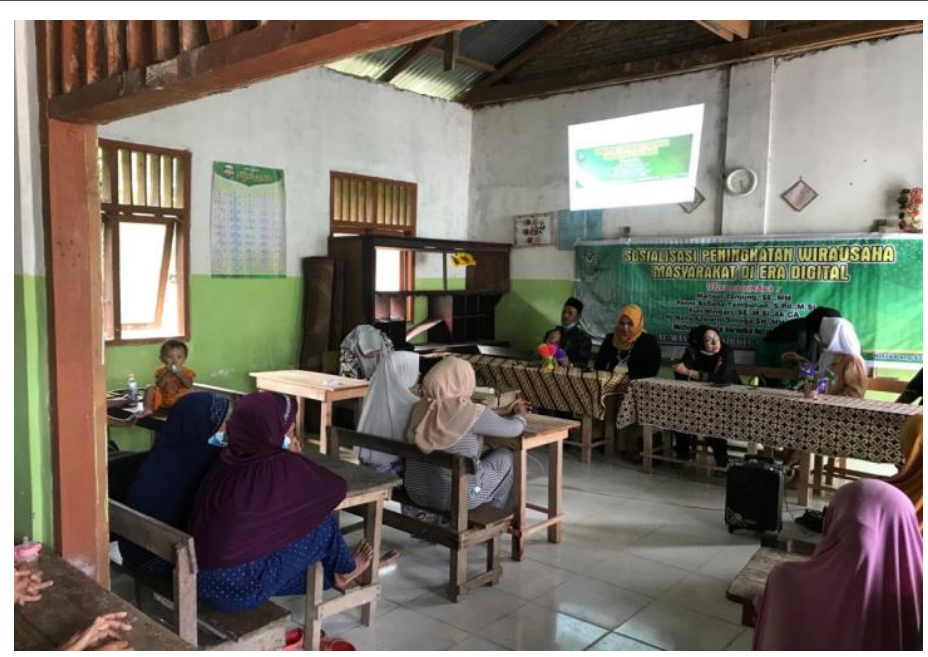

Gambar 1: Kata Sambutan Bapak Mansur Tanjung dan pemberian materi dengan materi gambaran umum wirausaha masyarakat di Era Digital.

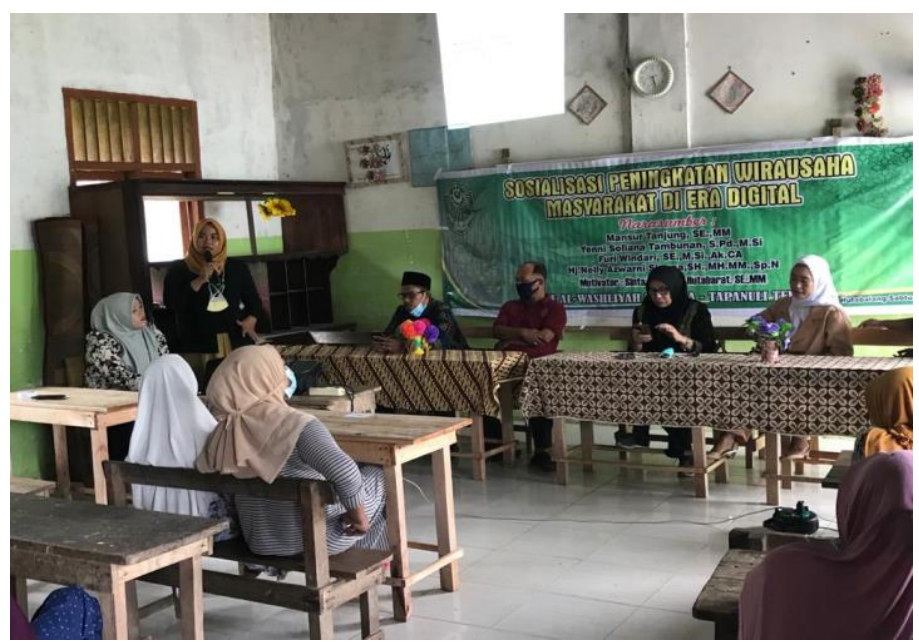

Gambar 2: Ibu Yenni Sofiana Tambunan memberikan materi peluang usaha yang memungkinkan di daerah Kelurahan Huta Balang dengan sarana Digital

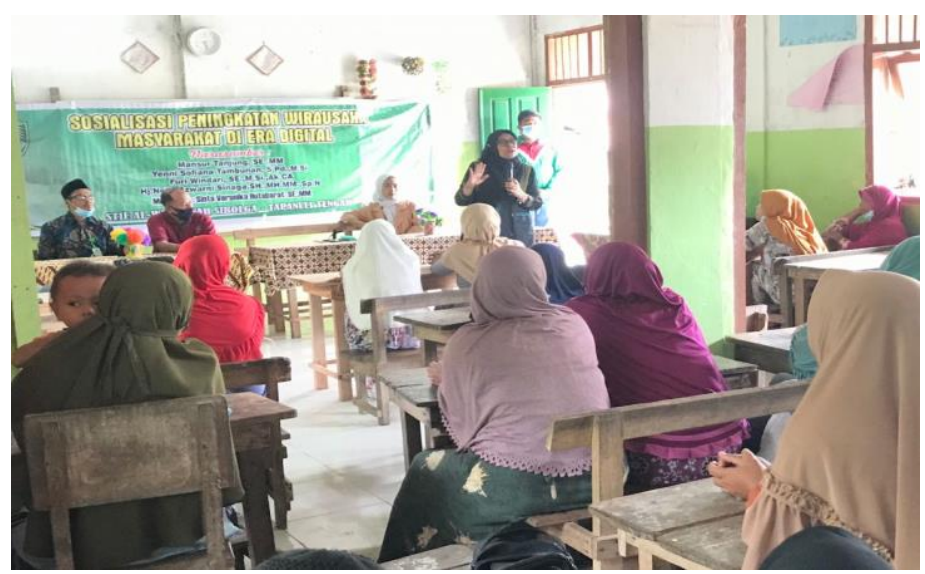

Gambar 3 : Ibu Nelly Azwarni Sinaga memberikan materi tentang Etika hukum dalam bisnis Digital. 


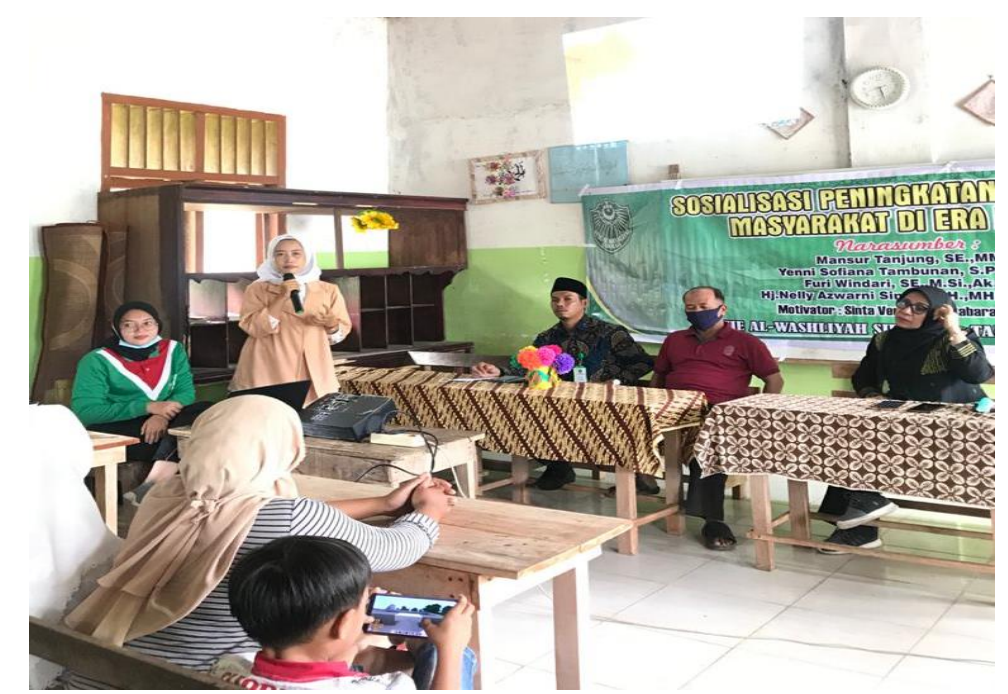

Gambar 4 : Dosen Furi Windari memberikan materi tentang Laporan Keuangan Bisnis Wirausaha.

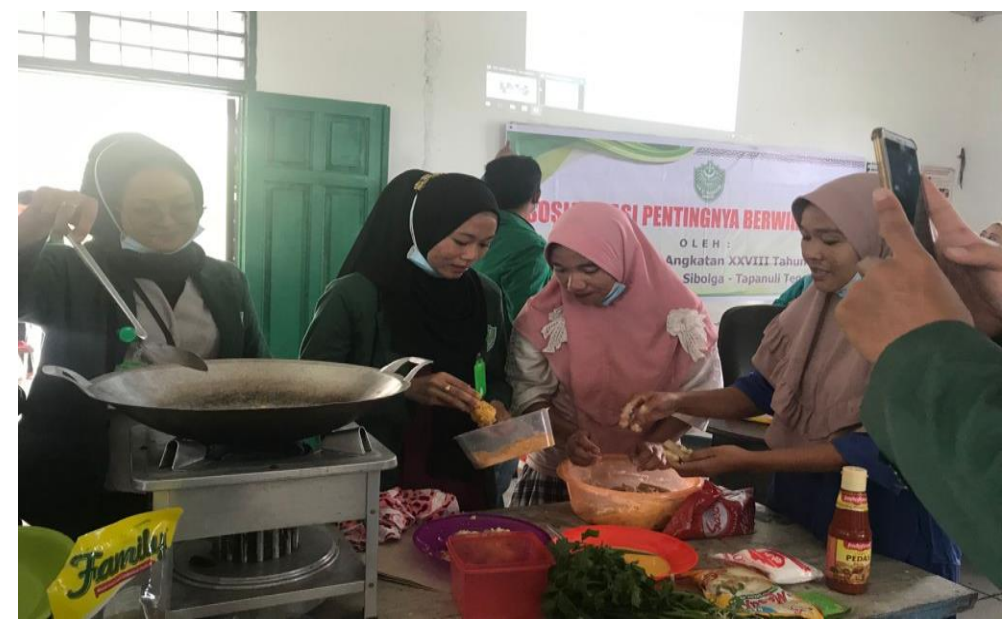

Gambar 5 : Praktek pembuatan sosis dari ikan dengan ibu-ibu Kelurahan Huta Balang, Kecamatan Badiri, Kabupaten Tapanuli Tengah, yang dibantu oleh Mahasiswa.

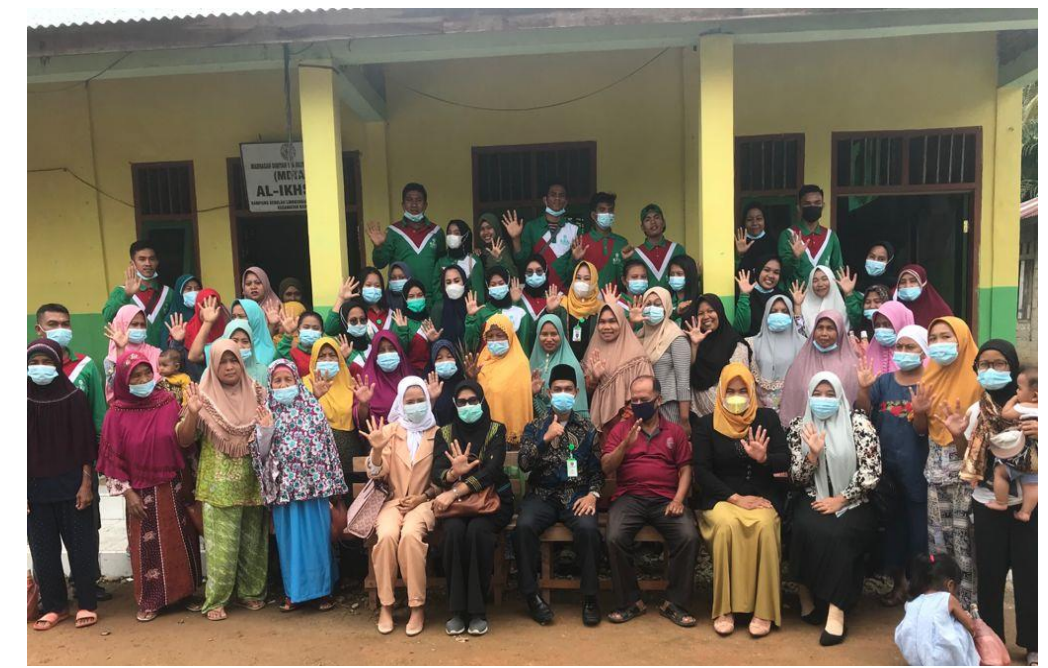

Gambar 6 : Foto Bersama antara Narasumber dengan Masyarakat. 


\section{Hasil}

Output yang didapat dari kegiatan Pengabdian kepada Masyarakat ini diantaranya adalah :

1. Masyarakat diberikan pemahaman (sosialisasi) mengenai pengertian digital, beberapa peluang usaha, pengelolaan keuangan bisnis rumahan, perencanaan bewirausaha yang baik dan benar.

2. Dari hasil sosialisasi, masyarakat memahami mengenai isi materi dan di akhir sesi diberikan waktu tanya jawab. Didapatkan beberapa pertanyaan dari masyarakat diantaranya :

a. Bagaimanakah kiat memilih usaha yang peluang bertahannya lebih besar?

b. Bagaimana cara menangani kendala - kendala yang dihadapi dengan menganggunakan sarana digital?

c. Bagaimana aturan hukum di era digital dan pemahaman pembeli dan penjual?

d. Bagaimana penyususna laporan keuangan yang mudah dipahami?

3. Untuk mengevaluasi tingkat pemahaman masyarakat terhadap isi materi sosialisasi, maka diberikan beberapa pertanyaan terkait isi materi sosialisasi dan masyarakat dipersilahkan untuk dijawab masyarakat, yang berhasil menjawab pertanyaan dengan benar diberikan door prize sebagai tanda apresiasi.

Sedangkan outcome yang didapatkan diantaranya adalah :

1. Dengan adanya program Pengabdian kepada Masyarakat yang berupa sosialisasi meningkatkan wirausaha masyarakat di era digital diharapkan dapat meningkatkan pengetahuan masyarakat tentang usaha di masa digital sekarang ini, penyusunan laporan keuangan usaha yang benar, hukum dalam perdagangan dengan E-Commerce dan mengerti bagaimana caranya bergabung pada aplikasi E-Commerce.

2. Lebih jauh, diharapkan kegiatan-kegiatan serupa dapat berdampak pada peningkatan kesadaran masyarakat Indonesia khususnya pada Ibu-ibu Kelurahan Huta Balang, Kecamatan Badiri, Kabupaten Tapanuli Tengah.

3. Sekolah Tinggi Ilmu Ekonomi (STIE) Al Washliyah Sibolga/Tap.Tengah khususnya Program Studi Manajemen Perusahaan semakin dikenal sebagai Perguruan Tinggi yang mempunyai kepedulian terhadap permasalahan masyarakat khususnya.

\section{Kesimpulan}

Laporan kegiatan Pengabdian kepada Masyarakat oleh Tim Dosen Sekolah Tinggi Ilmu Ekonomi Al Washliyah Sibolga/Tap.Tengah dilaksanakan sesuai dengan tujuan dan rencana. Kegiatan ini mendapat sambutan yang baik dari masyarakat yaitu IRT dan Pemerintah daerah setempat, yaitu Lurah dan Kepling. Kegiatan ini dapat memberikan tambahan semangat dan pengetahuan tentang peluang usaha IRT yang tidak harus susah payah menjual usaha kreativitasnya ke pembeli hanya dengan memanfaatkan industri e-commerce di era digital saat ini.

\section{Daftar Pustaka}

Adri, M., Hanesman, Sriwahyuni, T.,\& Almasri. (2019). Al Marketing Sebagai Metoda Alternatif Wirausaha Bagi Mahasiswa di Universitas Negeri Padang. Jurnal Teknologi Informasi dan Pendidikan. Vol. 12, No. 2, 2019

Atmaja, Hanung Eka \& Verawati, Dian Marlina. 2021. MENINGKATKAN MINAT KEWIRAUSAHAAN DI ERA GLOBAL MELALUI E-COMMERCE. Jurnal Bisnis dan Akuntansi Unsurya Vol. 6, No. 1, Januari 2021.

Maryati, Wiwik \& Masriani, Ida. (2019). Peluang Bisnis di Era Digital Bagi Generasi Muda Dalam Berwirausaha: Strategi Menguatkan Perekonomian. Jurnal Manajemen dan Bisnis. Volume 4, Nomor 2 Desember 2019, pp. 53-58.

Menkop UKM: Menjadi Wirausaha Adalah Pilihan Tepat. Diakses pada 21 Oktober 2020, dari Bisnis.com. $\quad$ https://ekonomi.bisnis.com/read/20201021/9/1308257/menkopukm-menjadiwirausaha-adalah-pilihan-tepat. 
Novita, Yustina Dhian \& Santoso, Budi. 2021. Urgensi Pembaharuan Regulasi Perlindungan Konsumen di Era Bisnis Digital. Jurnal Pembangunan Hukum Indonesia, Volume 3, Nomor 1, Tahun 2021, halaman 46-58

Pertumbuhan Ekonomi dan Investasi Digital di Indonesia Dalam Perspetif Hukum. (8 Juli 2021). Fakultas Hukum Universitas Islam Indonesia Yokyakarta. https://law.uii.ac.id/blog/2021/07/08/pertumbuhan-ekonomi-dan -investasi-di-indonesia-dalamperspetif-hukum/.

Undang-Undang Republik Indonesia Nomor 20 Tahun 2003 Tentang Sistem Pendidikan Nasional. Sistem Pendidikan Nasional. Diakses pada 25 Agustus 2021, dari https://peraturan.bpk.go.id/Home/Details/43920/uu-no-20-tahun-2003. 


\section{LAMPIRAN}

Surat Pengantar Lembaga Penelitian Dan Pengabdian Kepada Masyarakat

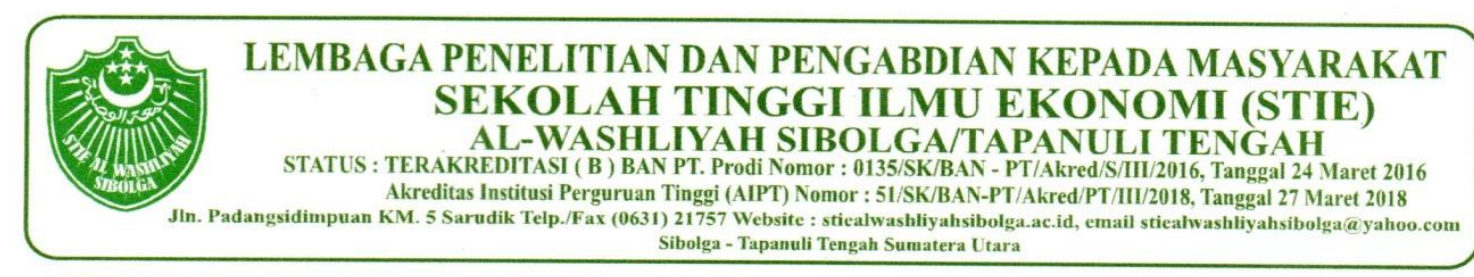

No : 192/LP2M/STIE-AW/IIL/2021

Sibolga, 25 Maret 2021

Lamp : -

Hal : Pelaksanaan Tri Dharma Perguruan Tinggi

Kepada Yth :

Bapak/ibu Dosen STIE Al-Washliyah

Sibolga/Tapanuli Tengah

di -

Tempat

Assalamu'alaikum Wr. Wb

Dengan Hormat.

Diberitahukan kepada Bapak/Ibu Dosen bahwasannya disamping melakukan pengajaran Bapak/Ibu Dosen juga melaksanakan kegiatan "Penelitian dan Pengabdian Kepada Masyarakat". Dimana kegiatan Penelitian dan Pengabdian Kepada Masyarakat merupakan salah satu Tri Dharma Perguruan Tinggi. Dan diharapkan agar hasil/output dari kegiatan penelitian dan pengabdian kepada masyarakat dipublikasikan pada Jurnal Ilmiah

Demikian surat pemberitahuan ini kami sampaikan agar bapak/ibu Dosen dapat bekerja sama didalam kegiatan Penelitian dan Pengabdian kepada Masyarakat yang merupakan salah satu dari Tri Dharma Perguruan Tinggi, atas kerjasamanya kami ucapkan terima kasih

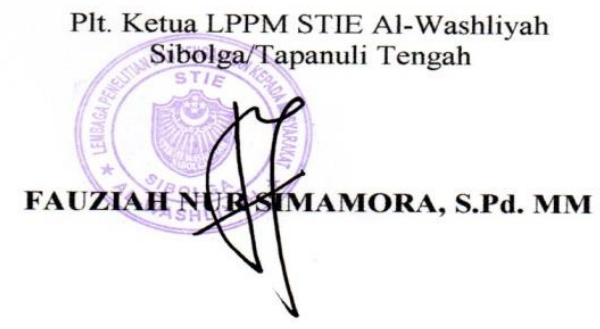

Surat permohonan audensi untuk melakukaan PkM kepada lurah Huta Balang 

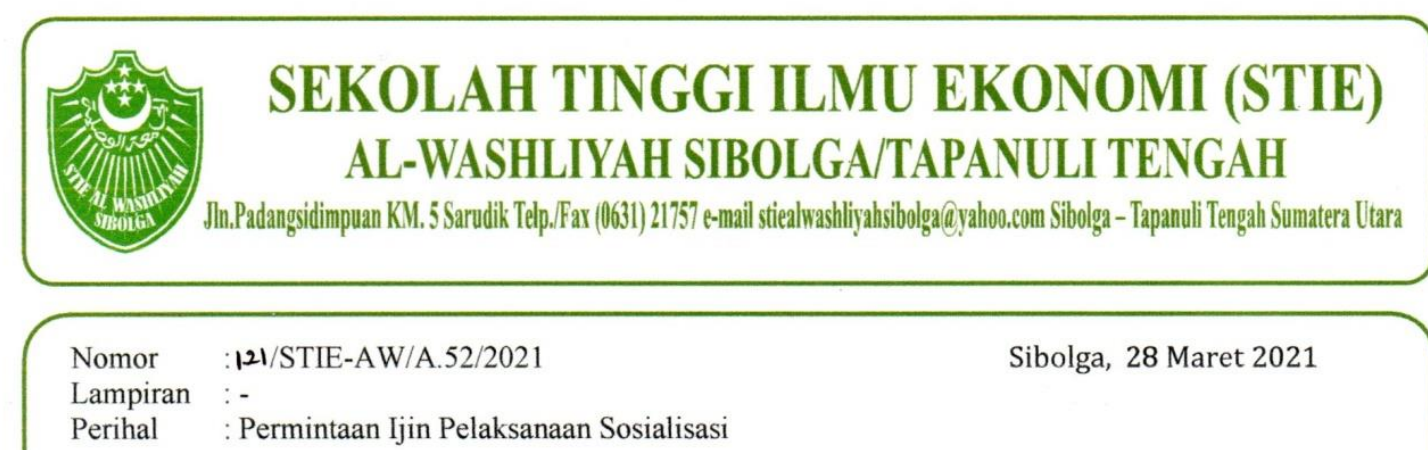

Kepada Yth,

Bapak Lurah

Kelurahan Huta Balang

di

Tempat

Dengan Hormat,

1. Kami do'akan semoga Bapak dan seluruh jajaran pemerintah Kelurahan Huta Balang, Kabupaten Tapanuli Tengah berada dalam lindungan Allah SWT. Amin.

2. Bersama dengan surat ini, Tim Dosen STIE Al Washliyah Sibolga/Tap.Tengah ingin mengajukan permohonan Ijin untuk melaksanakan Pengabdian Kepada Masyarakat dalam bentuk Sosialisasi dengan tema "Meningkatl Wirausaha Masyarakat di Era Digital".

3. Untuk itu kami akan melakukan Audensi ke kantor Bapak, yang akan diadakan pada:

$\begin{array}{ll}\text { Hari } & : \text { Kamis, } 01 \text { April } 2021 \\ \text { Pukul } & : \text { 09.30Wib s/d Selesai }\end{array}$

4. Demikian kami sampaikan, atas perhatian dan kerjasama yang baik diucapkan terima kasih

Diketahui

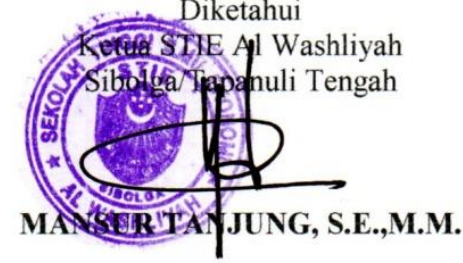

Ketua Tim

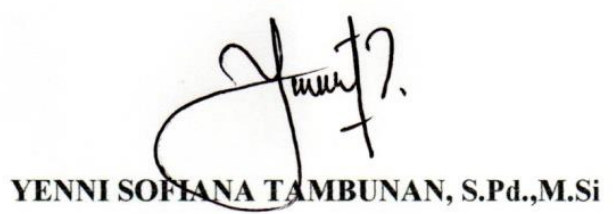

Absensi Saat Sosialisasi

\begin{tabular}{|c|c|c|}
\hline NO & NAMA & $\begin{array}{c}\text { TANDA } \\
\text { TANGAN }\end{array}$ \\
\hline 1 & SURIP & $3 \ln i$ \\
\hline 2 & TGTA & $2 \mathrm{ln}$ \\
\hline 3 & SINATA & 3hus \\
\hline
\end{tabular}




\section{HALAMAN PENGESAHAN}

Telah dilaksanakan kegiatan Pengabdian kepada Masyarakat (PkM) yang dilakukan oleh Dosen Sekolah Tinggi Ilmu Ekonomi (STIE) Al Washliyah 
